\title{
OCORRÊNCIA DE FOSFATO DE TERRAS RARAS NA FORMAÇÃO RESENDE, PALEÓGENO DO RIFT CONTINENTAL DO SUDESTE DO BRASIL
}

\author{
Lucy Gomes SANT'ANNA \\ Claudio RICCOMINI \\ José Vicente VALARELLI $(\dagger)$
}

\begin{abstract}
RESUMO
A partir de estudos petrográficos e análises por MEV/EDS e DRX foi identificado fosfato de cálcio e terras raras ( $\mathrm{La}, \mathrm{Nd})$ em depósito de lamito argilo-arenoso da Formação Resende, situado na borda norte da bacia homônima. Tendo em vista suas características morfológicas (hábito prismático hexagonal) e composição química, este mineral foi atribuído ao grupo do rabdofầnio. Este fosfato é autigênico e sua origem é relacionada à dissolução de apatita detrítica, provavelmente a partir de soluções hidrotermais alcalinas, as quais teriam ainda fornecido parte dos elementos necessários a sua cristalização.

Palavras-chave: fosfato, elementos terras raras, rabdofầnio, Bacia de Resende, Brasil.
\end{abstract}

\section{ABSTRACT}

Petrographic studies and SEM/EDS and XRD analyses revealed the presence of a phosphate with $\mathrm{Ca}$ and $\mathrm{REE}$ ( $\mathrm{La}, \mathrm{Nd}$ ) in a mudstone deposit of the Resende Formation, located on the northern border of the Resende Basin. The morphological characteristics (prismatic hexagonal habit) and chemical composition of the phosphate allow including this mineral in the rhabdophane group. This phosphate is authigenic and its origin is related to the dissolution of detritic apatite grains, probably by alkaline hydrothermal solutions. These solutions also provided some of the elements involved in the rhabdophane crystalization.

Keywords: phosphate, rare-earth elements, rhabdophane, Resende Formation, Brazil.

\section{INTRODUÇÃO}

Os fosfatos de terras raras pertencem em sua ampla maioria aos grupos da monazita, xenotima, florencita e do rabdofânio. Estes fosfatos constituem minerais primários em rochas ígneas e metamórficas, detríticos em rochas sedimentares, ou ainda residuais ou secundários em solos (DIXON \& WEED 1989, GAINES et al. 1997, KLEIN \& HURLBUT JR. 1999).

A monazita ocorre geralmente como mineral acessório em granitos, gnaisses, aplitos e pegmatitos e como grãos detríticos em areias e arenitos (KLEIN \& HURLBUT JR. 1999). A xenotima apresenta-se como acessório em rochas ígneas ácidas e alcalinas, e em gnaisses ricos em mica e quartzo, além de estar presente nas porções pegmatíticas associadas a estas rochas (NRIAGU 1984). Florencita é encontrada em micaxistos, pegmatitos e como mineral detrítico em areias e arenitos (NRIAGU 1984, GAINES et al. 1997). Estes fosfatos ocorrem ainda em perfis de alteração, como minerais detríticos ou supergênicos (e.g. SLUKIN 1994, DE PUTTER et al. 1999). Existem ainda referências à formação destes fosfatos em depósitos afetados parcial ou totalmente por hidrotermalismo (e.g. KRAVCHENKO \& POKROVSKY 1995).

Rabdofânio, considerado um mineral de baixa temperatura análogo da monazita monoclínica (MOONEY 1950), tem sido descrito como produto de alteração hidrotermal associa- 
da a corpos pegmatíticos e eventos tardios de erupções vulcânicas (e.g. FODOR et al. 1987)

alteração de outros fosfatos, como apatita ou mineral supérgeno formado a partir da

(BANFIELD \& EGGLETON 1989) e allanita (MEINTZER \& MITCHELL 1988).

\begin{tabular}{|c|c|c|c|c|}
\hline GRUPO & FÓRMULA GERAL & ÍONS CONSTITUINTES & $\begin{array}{c}\text { SISTEMA } \\
\text { CRISTALINO } \\
\end{array}$ & $\begin{array}{c}\text { GRUPO } \\
\text { ESPACIAL }\end{array}$ \\
\hline Monazita & $\mathrm{ATO}_{4}$ & $\begin{aligned} \mathrm{A} & =\mathrm{Ce}^{3+}, \mathrm{La}, \mathrm{Nd}, \mathrm{Th}^{4+}, \mathrm{Ca}, \mathrm{Bi}, \mathrm{ETR} \\
\mathrm{T} & =\mathrm{P}, \mathrm{As}\end{aligned}$ & Monoclínico & $\mathrm{P} 2 / \mathrm{n}$ \\
\hline Xenotima & (ETR) $\mathrm{TO}_{4}$ & $\begin{array}{l}\mathrm{ETR}=\mathrm{Y}, \mathrm{Ce} / \mathrm{Bi} \\
\mathrm{T}=\mathrm{P}, \mathrm{As}, \mathrm{V}, \mathrm{Si}\end{array}$ & Tetragonal & $\mathrm{I} 4_{1} / \mathrm{amd}$ \\
\hline Florencita & $\mathrm{AB}_{3}\left(\mathrm{TO}_{4}\right)_{2}(\mathrm{OH})_{5 \text { ou } 6}$ & $\begin{array}{l}\mathrm{A}=\mathrm{ETR}, \mathrm{Ba}, \mathrm{Bi}, \mathrm{Ca}, \mathrm{Th}, \mathrm{Pb} \\
\mathrm{B}=\mathrm{Al}, \mathrm{Fe}^{3+}\end{array}$ & Trigonal & $\mathrm{R} 3 \mathrm{~m}$ \\
\hline & & $\begin{array}{l}\mathrm{T}=\mathrm{As}, \mathrm{P} /(\mathrm{OH}) \text { dependendo da carga } \\
\text { do íon A }\end{array}$ & & \\
\hline Rabdofânio & $\mathrm{APO}_{4} \cdot \mathrm{H}_{2} \mathrm{O}$ & $\mathrm{A}=\mathrm{Ce}, \mathrm{La}, \mathrm{Nd}, \mathrm{Th}, \mathrm{Ca}, \mathrm{U}, \mathrm{Fe}^{3+}$ & $\begin{array}{l}\text { Hexagonal ou } \\
\text { ortorrômbico }\end{array}$ & $\begin{array}{l}\mathrm{P} 6^{2} 22 \text { (Hex) } \\
\text { P222 (Ort) }\end{array}$ \\
\hline
\end{tabular}

TABELA 1 - Características cristaloquímicas dos principais grupos de fosfatos de terras raras (NRIAGU 1984, GAINES et al. 1997).

Os principais dados cristaloquímicos destes grupos encontram-se sumariados na tabela 1 .

Neste trabalho é descrita a ocorrência de um mineral fosfático contendo cálcio e terras raras, provavelmente pertencente ao grupo do rabdofânio, em lamito argilo-arenoso da Formação Resende, na bacia homônima, cuja origem é aqui atribuída a processo hidrotermal.

\section{GEOLOGIA DA FORMAÇÃO RESENDE}

A Formação Resende, definida inicialmente por AMADOR (1975), de idade eocênica-oligocênica (RICCOMINI et al. 1983, LIMA \& AMADOR 1985, RICCOMINI 1989, LIMA et al. 1994, YAMAMOTO 1995), compreende um sistema de leques aluviais associados a planícies aluviais de rios entrelaçados, originado durante a fase de instalação do Rift Continental do Sudeste do Brasil (RCSB) (RICCOMINI 1989). Este rift apresenta-se como uma faixa estreita, alongada na direção ENE, desenvolvida entre as cidades de Curitiba (PR) e Barra de São João (RJ), tendo as bacias de Curitiba, São Paulo, Taubaté, Resende, Volta Redonda (RICCOMINI \& COIMBRA 1992) e do Macacu (FERRARI \& SILVA 1997) como principais sítios deposicionais (Fig. 1).

O preenchimento vulcano-sedimentar paleogênico do RCSB foi englobado no Grupo
Taubaté (RICCOMINI 1989), tendo a Formação Resende como unidade basal, a qual apresenta distribuição generalizada nas principais bacias acima mencionadas, onde é representativa da sedimentação que acompanhou os eventos tectônicos geradores do rift. Derrames de lavas ankaramíticas, datadas de 42Ma (RICCOMINI et al. 1983), estão intercalados em lamitos da Formação Resende na Bacia de Volta Redonda, e registram a atividade vulcânica durante $o$ preenchimento do RCSB. O Grupo Taubaté inclui ainda os depósitos lacustres da Formação Tremembé e fluviais meandrantes da Formação São Paulo, ambos oligocênicos e interdigitados lateralmente com os pacotes superiores da Formação Resende (Fig. 2).

A Bacia de Resende é um hemi-graben, cujo embasamento é composto essencialmente por rochas gnáissico-migmatíticas de médio a alto grau metamórfico, de idade arqueana a proterozóica, referíveis ao Complexo Paraíba do Sul (MACHADO FILHO et al. 1983). Rochas metassedimentares de baixo a médio grau metamórfico e granitóides, ambas proterozóicas, ocorrem, respectivamente, nas bordas sudeste e norte da bacia (IPT 1983). Três grandes corpos alcalinos mesozóicos, compostos essencialmente por nefelina-sienitos, são encontrados nas vizinhanças da Bacia de Resende, compreendendo os maciços de Itatiaia (idade $\mathrm{K} / \mathrm{Ar}$ de 73Ma, LAUAR 1988) e Passa Quatro (idade $\mathrm{Rb} / \mathrm{Sr}$ de 70,3Ma, LAUAR 1988), situados nas proximidades da borda norte da bacia, e o Maciço do Morro Redondo (idade K/Ar de 
67,2Ma, SONOKI \& GARDA 1988) localizado na borda sul (Fig. 3).

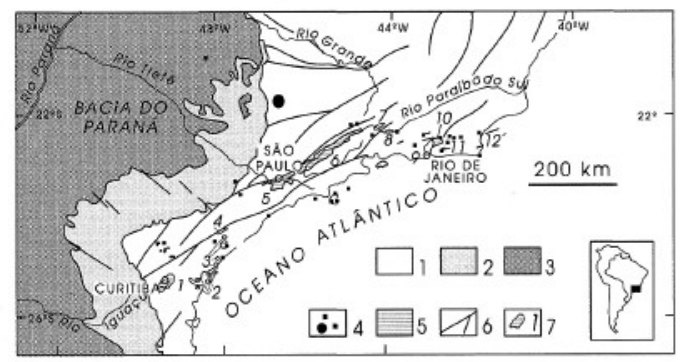

FIGURA 1 - Quadro geológico e tectônico regional do Rift Continental do Sudeste do Brasil-RCSB (MELO et al. 1985, RICCOMINI et al. 1996, FERRARI \& SILVA 1997). 1) embasamento pré-cambriano; 2) rochas sedimentares paleozóicas e mesozóicas da Bacia do Paraná; 3) rochas relacionadas ao vulcanismo da Formação Serra Geral, em parte recobertas por sedimentos e, nesses últimos, algumas intercalações de lavas alcalinas; 4) rochas relacionadas ao magmatismo Mesozóico-Cenozóico; 5) sedimentos terciários do RCSB; 6) zonas de cisalhamento relacionadas ao Ciclo Brasiliano - Pan-Africano, em parte reativadas pelo menos durante o Mesozóico e Cenozóico; 7) bacias do rift (1-Bacia de Curitiba, 2Formação Alexandra e Graben de Guaraqueçaba, 3Formação Pariqüera-Açu, 4-Graben de Sete Barras, 5Bacia de São Paulo, 6-Bacia de Taubaté, 7-Bacia de Resende, 8-Bacia de Volta Redonda, 9-Graben da Guanabara, 10-Bacia do Macacu, 11- Bacia de Itaboraí, 12-Graben de Barra de São João).

A evolução da Bacia de Resende foi controlada por falhas do seu embasamento. Falhas de direção ENE, que delimitam a borda norte da bacia, são produto de reativação de antigas zonas de cisalhamento proterozóicas, as quais foram locais preferenciais para processos de silicificação, provavelmente ocorridos em mais de uma fase e relacionados aos eventos tardios do magmatismo alcalino mesozóicocenozóico (IPT 1983). Durante o EocenoOligoceno ocorreu nova reativação destas falhas, concomitante à deposição da Formação Resende, quando atuaram como um dos fatores essenciais na distribuição litológica dos depósitos dessa unidade.

As principais litofácies da Formação Resende correspondem a diamictitos e conglomerados nas porções proximais do sistema de leques aluviais, e lamitos arenosos a argilosos nas posições distais, existindo a transição entre elas nas porções medianas dos leques. Calcretes pedogenéticos ocorrem nos pacotes lamíticos arenosos a argilosos (COIMBRA \& RICCOMINI 1985). Arenitos grossos a médios, com estratificações cruzadas acanaladas de médio porte, são representativos da sedimentação em planície aluvial de rios entrelaçados. As fácies de diamictitos e conglomerados da Formação Resende situam-se nas posições basais e laterais do rift, em estreita relação com as zonas de falhas que limitam as depressões, e as fácies de lamitos arenosos a argilosos e arenitos nas porções mais interiores das bacias.

Posteriormente, no Neógeno, as estruturas de direção ENE e outras de direção WNW e NNE a NE, estas últimas também herdadas de foliações miloníticas do embasamento, foram reativadas uma vez mais, deformando tanto o pacote sedimentar da Formação Resende como as coberturas sedimentares mais jovens (colúvios, alúvios, stone-lines, dentre outras) (RICCOMINI 1989).

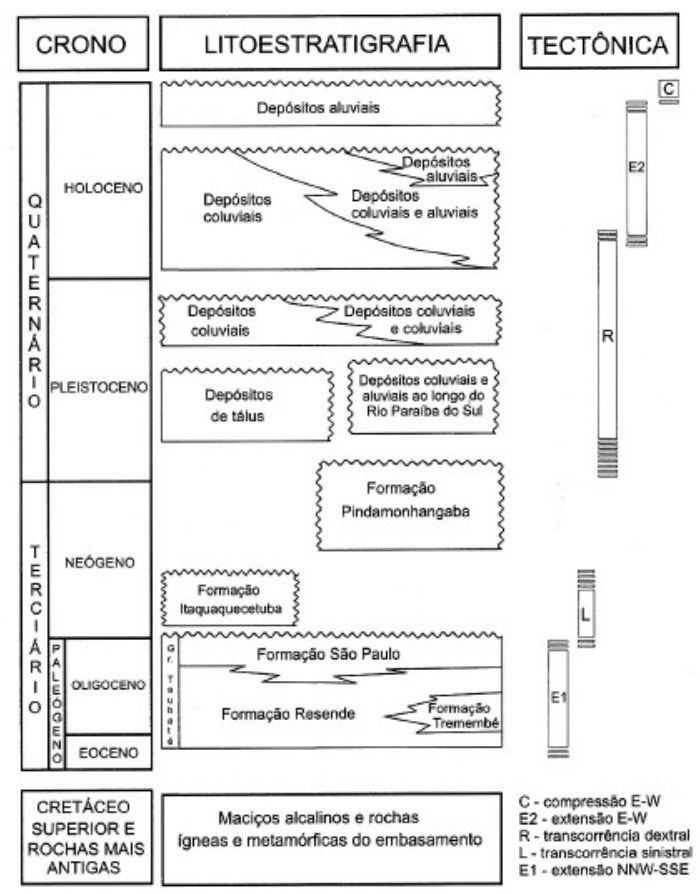

FIGURA 2 - Quadro litoestratigráfico e evolução tectono-sedimentar do Rift Continental do Sudeste do Brasil (RICCOMINI et al. 1996).

\section{MATERIAIS E MÉTODOS}

Estudos petrográficos, em lâminas delgadas sem recobrimento por lamínula, foram realizados para a caracterização mineralógica e textural da rocha portadora de fosfatos, no Laboratório de Petrografia Sedimentar do Departamento de Geologia Sedimentar e 
Ambiental do Instituto de Geociências da Universidade de São Paulo (GSA/IG-USP), utilizando-se Microscópio Óptico Axioplan 2 da Zeiss e analisador de imagens Leica QWin equipado com câmera CCD.

A caracterização do mineral fosfático foi efetuada em microscópio eletrônico de varredura com microanálise pontual por energia dispersiva acoplada (MEV/EDS). Para estas análises foram empregados os microscópios das marcas JEOL, modelo JSM-T330A, instalado no Núcleo de Pesquisas em Geoquímica e Geofísica da Litosfera (NUPEGEL) da USP, e LEO, modelo 440i, do GSA/IG-USP. As análises foram realizadas em amostras indeformadas, previamente metalizadas com carbono sobre um suporte de alumínio.

Análise por difração de raios X (DRX) em rocha total foi realizada em Difratômetro Siemens D5000, instalado no Laboratório de Difração de Raios X do Departamento de
Mineralogia e Geotectônica do IG-USP, operando com radiação $\mathrm{CuK} \alpha 40 \mathrm{kV}, 40 \mathrm{~mA}$, e goniômetro em condições rotineiras com velocidade de $2^{\circ} 2 \theta / \mathrm{min}$, passo de $0,05^{\circ}$ e tempo de contagem em 0,5 segundo.

\section{DESCRIÇÃO DA OCORRÊNCIA}

O mineral fosfático aqui descrito, inicialmente referido por SANT'ANNA (1999), foi identificado em depósito representativo do sistema de leques aluviais medianos da Formação Resende, situado próximo à borda norte da bacia homônima, cerca de $7 \mathrm{~km}$ a nordeste da Cidade de Resende (RJ) (Fig. 3). A ocorrência está localizada nas proximidades da interseção de falhas de direção WNW e NE, relacionadas à fase de reativação neogênica.

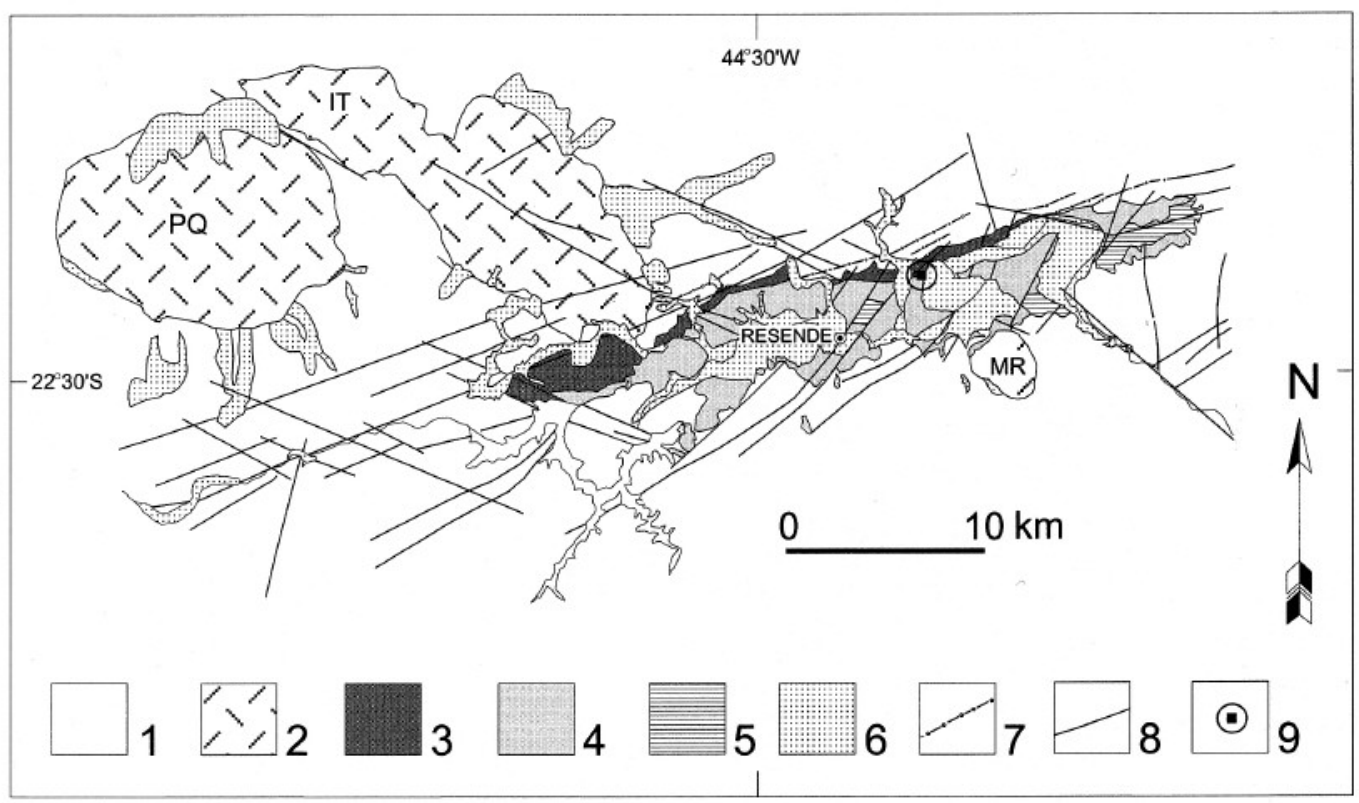

FIGURA 3 - Mapa geológico da Bacia de Resende (RJ) (RICCOMINI 1989): 1- embasamento pré-cambriano; 2- maciços alcalinos de rochas alcalinas neocretáceas (PQ- Passa Quatro, IT-Itatiaia, MR- Morro Redondo); 3sistema de leques aluviais proximais da Formação Resende; 4- sistema de leques aluviais medianos a distais e planície aluvial de rios entrelaçados da Formação Resende; 5- sistema fluvial meandrante da Formação São Paulo; 6- sedimentos colúvio-aluviais quaternários; 7- faixas de rochas silicificadas; 8- principais falhas cenozóicas; 9- localização da ocorrência de fosfato descrita neste trabalho.

A seção colunar da figura 4A ilustra a exposição, onde estão bem preservadas sucessivas corridas de lama de leques aluviais. $\mathrm{Na}$ base da exposição tem-se lamito arenoso conglomerático gradando, em direção ao topo, para lamito arenoso e lamito argilo-arenoso (A-C). Calcretes preenchendo rachaduras e vênulas de ressecação estão presentes no lamito argilo-arenoso (C). O lamito arenoso (B) e o lamito arenoso conglomerático (A) estão cimentados por calcita.

Na parte intermediária do corte ocorre espesso pacote de lamito argilo-arenoso (D), da porção superior de uma nova corrida de lama. No topo do afloramento tem-se lamito arenoso conglome- 
rático, com contato basal brusco, representativo da porção inferior de novo evento de deposição no contexto dos leques aluviais medianos.

Os lamitos apresentam cor verde-escura, dada pela fração argilosa que preenche os espaços intergranulares e ocorre em proporção variada nas diferentes fácies lamíticas. A argila é constituída por esmectita e caulinita, conforme indicado por difração de raios $\mathrm{X}$ (Fig. 4B).

Nas rochas lamíticas, a fração arenosa é composta por grãos angulosos de quartzo e
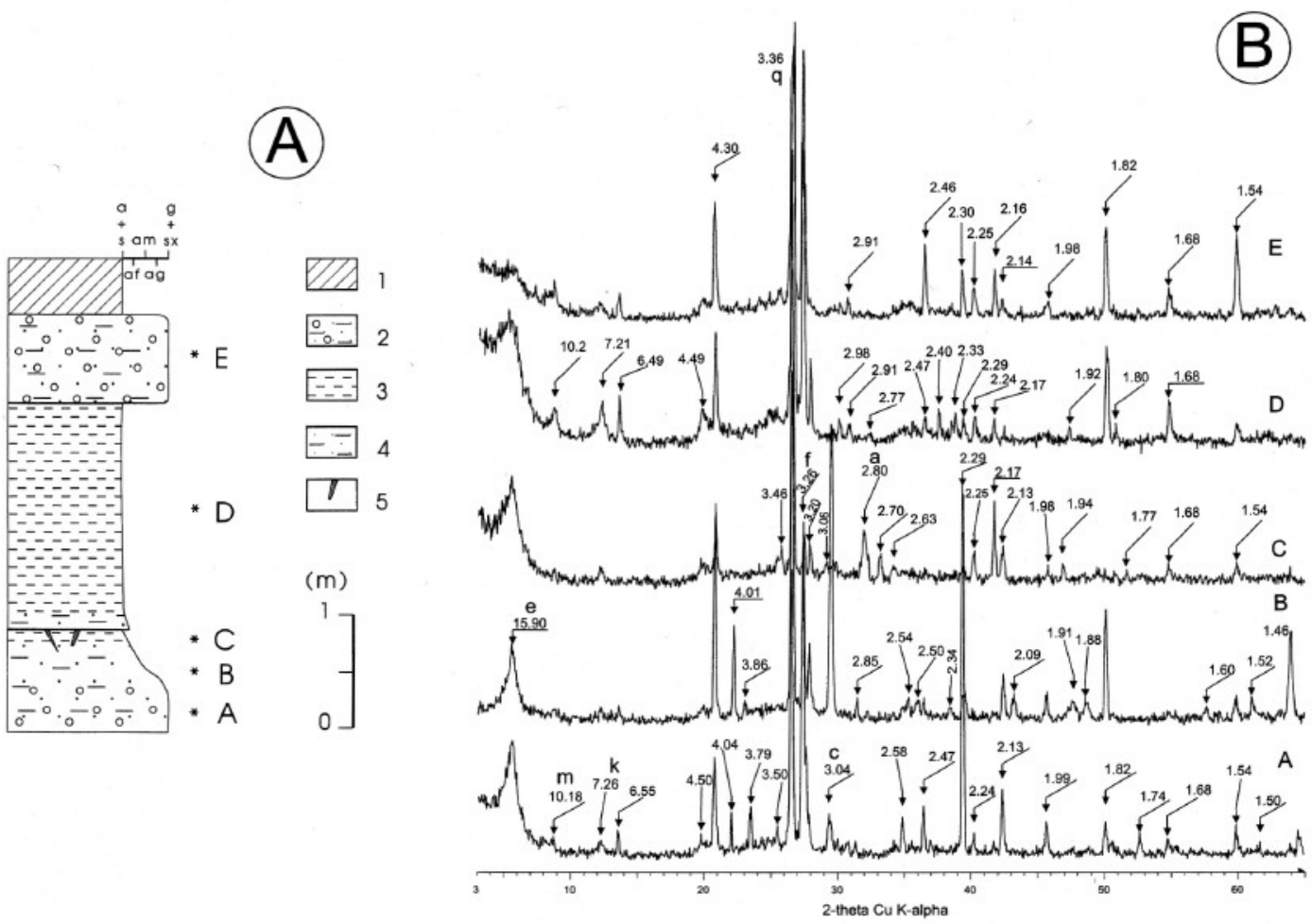

FIGURA 4 - (A) Seção colunar da Formação Resende: 1- solo recente; 2- lamito arenoso conglomerático; 3lamito argilo-arenoso; 4- lamito arenoso; 5- calcrete em rachadura. (B) Difratogramas de raios X de amostras totais, correspondentes à amostragem em (A). (Legenda no difratograma: a - apatita, c - calcita, e - esmectita, $\mathrm{f}$ - feldspato, $\mathrm{k}$ - caulinita, $\mathrm{m}$ - mica, q - quartzo.) (Nos difratogramas, os valores das reflexões estão expressos em angstrom.)

feldspato (1 a $0,1 \mathrm{~mm})$ e placas de mica $(0,4$ a $0,2 \mathrm{~mm}$ ), os quais apresentam contatos laterais ou pontuais em lâminas delgadas das fácies arenosas e estão disseminados na matriz de lamitos argilosos (Fig 5). Subordinadamente, ocorrem grãos de apatita $(<50 \mu \mathrm{m})$, em pequena proporção $(<1 \%)$, em geral inalterados. Quando alterados exibem feições de dissolução dos grãos mas com preservação da extinção reta e do hábito prismático (Figs 6A, 6B).

Grânulos e seixos ( 1 a $8 \mathrm{~mm})$ de quartzo, feldspato potássico e plagioclásio são abundantes nos níveis conglomeráticos.

A partir das análises via MEV/EDS dos lamitos argilo-arenosos (C) foi possível identificar fosfato de cálcio e terras raras, como cristais prismáticos hexagonais, euedrais, com aproximadamente $10 \mu \mathrm{m}$ de comprimento e cerca de 2

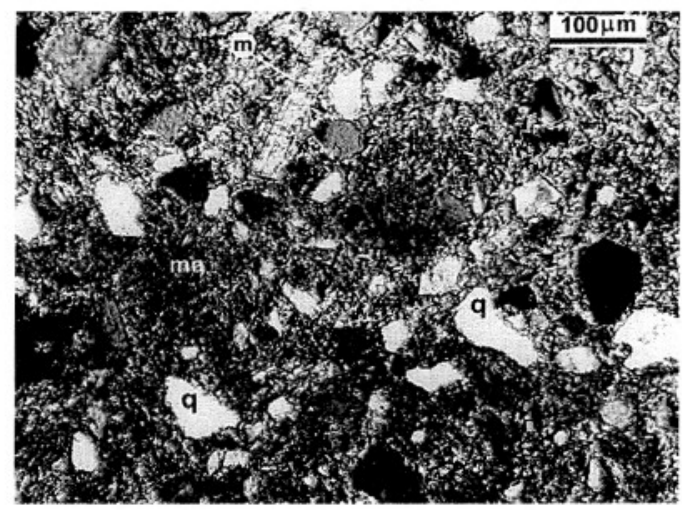

FIGURA 5 - Aspecto geral do lamito argiloarenoso, contendo placas de mica (m) e grãos angulosos de quartzo (q) e feldspato, localmente com contatos pontuais, disseminados na matriz argilosa (ma) (polarizadores cruzados) (amostra $\mathrm{C}$ da figura 4A). 

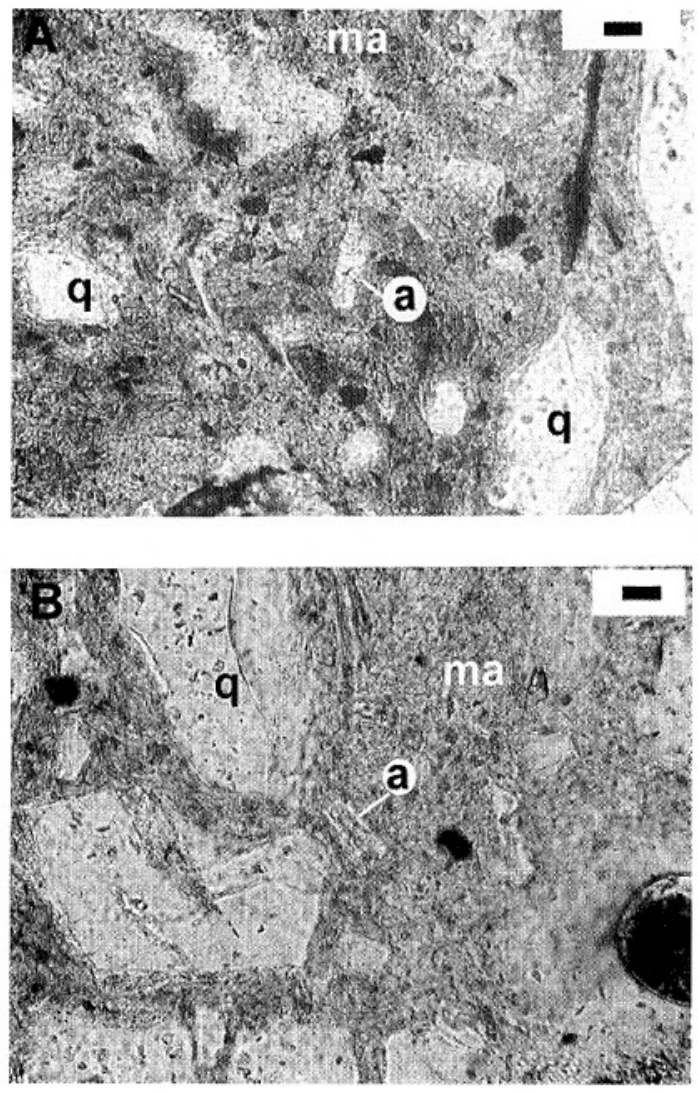

FIGURA 6 - Detalhe de grãos detríticos de apatita alterados: A - apatita com forte alteração, tendo a preservação de poucas partes do grão original, onde ainda se pode observar a extinção reta e o alto relevo (polarizadores paralelos); B - apatita completamente alterada, com preservação apenas do hábito prismático (polarizadores paralelos). (a- apatita, qquartzo, ma- matriz argilosa). (Nas figuras, o comprimento das barras representa $20 \mu \mathrm{m}$.)

a $3 \mu \mathrm{m}$ de diâmetro (Fig. 7A), contendo $\mathrm{Ca}$, $\mathrm{La}$ e Nd em sua composição (Fig. 7B). Estes fosfatos são crescidos em feixes junto à borda de grãos de quartzo e sobre a matriz argilosa (Fig. 8), e ainda recobrindo a superfície de grãos alterados de apatita detrítica (Fig. 9A). No contexto da Formação Resende, a distribuição destes minerais é restrita, tendo sido identificado, até o momento, apenas neste depósito.

Os estudos por difração de raios $\mathrm{X}$ para caracterização mineralógica do fosfato foram prejudicados pela pequena quantidade desse mineral na rocha. Assim, foram obtidos apenas difratogramas de raios $\mathrm{X}$ para rocha total de lamito argilo-arenoso, sem tratamento prévio, no qual a presença de mineral fosfático é sugerida pelas reflexões de $3,46 \AA 3,06 \AA, 2,80 \AA$, $2,70 \AA, 2,63 \AA, 2,25 \AA$ e $1,94 \AA$ (Fig. 4B, gráfico
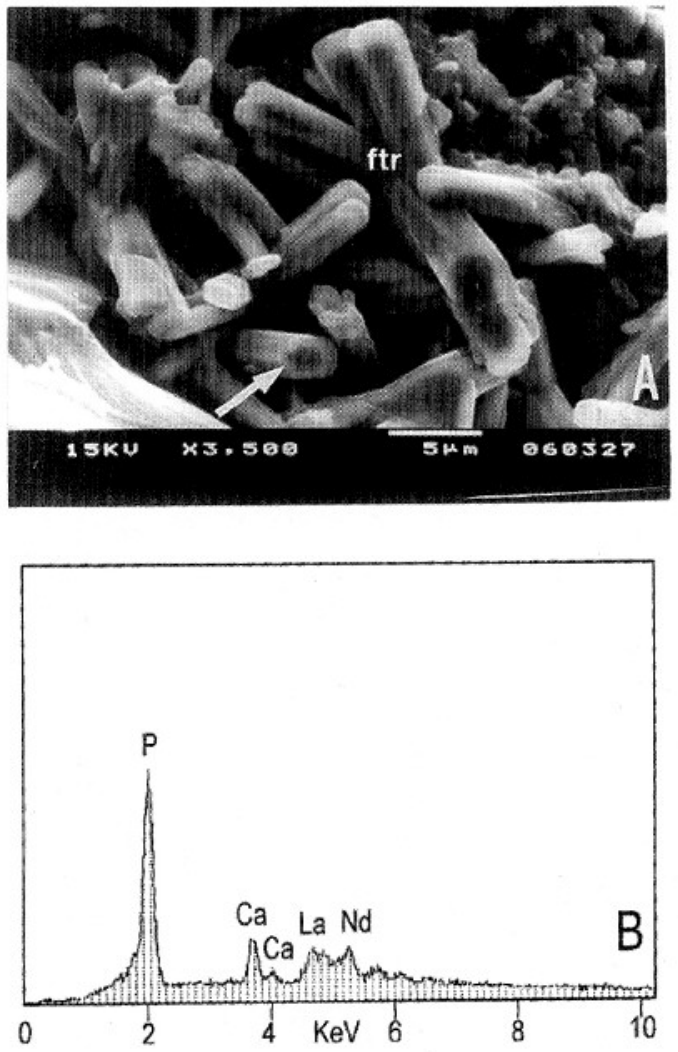

FIGURA 7 - (A) Imagem de MEV (sinal de elétrons secundários) detalhando o hábito prismático hexagonal dos cristais de fosfato de terras raras (ftr), evidenciado pela morfologia da seção basal (vide seta). (B) Espectro de EDS do fosfato de terras raras da figura (A).

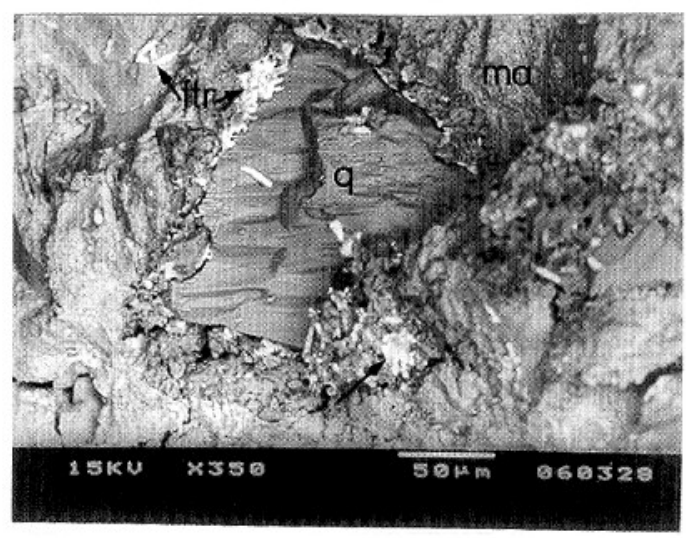

FIGURA 8 - Imagem de MEV (sinal de elétrons retroespalhados) mostrando cristais de fosfato de terras raras (ftr) crescidos sobre a matriz (ma) e junto à borda de grão detrítico de quartzo (q) (vide setas) no lamito argiloarenoso. 

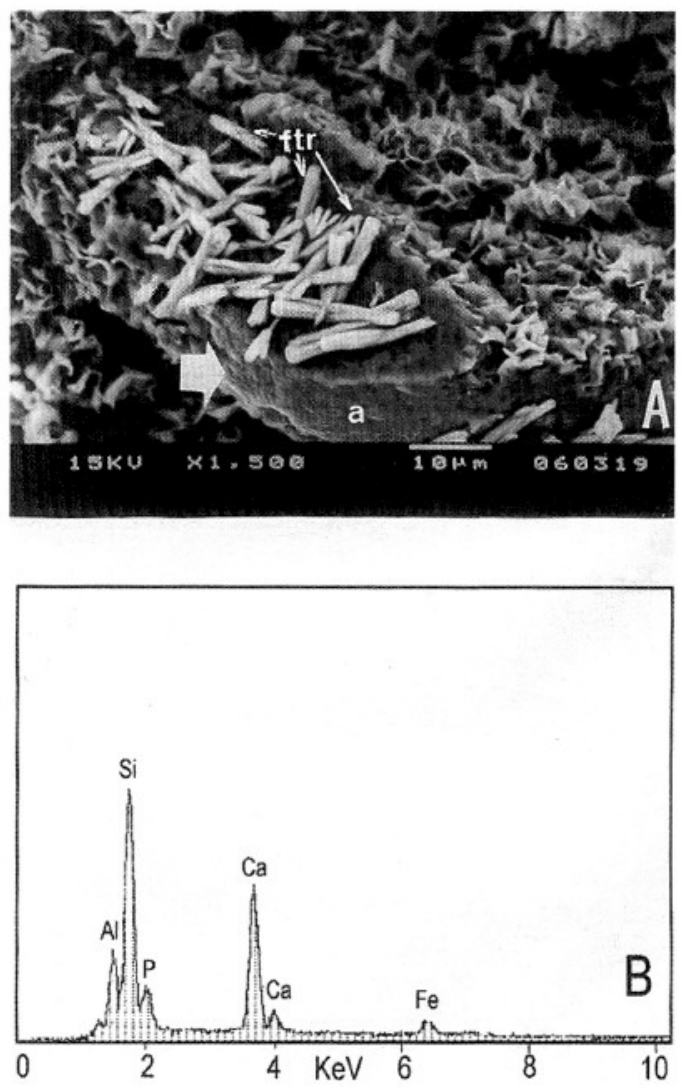

FIGURA 9 - (A) Imagem de MEV (sinal de elétrons secundários) mostrando grão de apatita detrítica (a) com dissolução nas bordas e tendo cristais de fosfato de terras raras (ftr) crescidos em feixes sobre sua superfície (vide setas). (B) Espectro de EDS da apatita detrítica da figura (A), sendo a presença de Al, Si e Fe devida à matriz argilosa nas proximidades da borda do grão.

C). Estes valores correspondem àqueles esperados para apatita, em concordância com a ficha de no 12-0529 do ICDD (International Center for Diffraction Data).

\section{DISCUSSÕES E INTERPRETAÇÕES}

As análises químicas obtidas para o fosfato de cálcio e terras raras ( $\mathrm{La}, \mathrm{Nd})$ encontrado na Formação Resende permitem atribuí-lo aos grupos da monazita ou do rabdofânio. Fica prejudicada a eventual relação com os grupos da xenotima, por esta não incorporar de forma preferencial Ca e ETR leves em sua composição, e da florencita que apresenta $\mathrm{Al}$ e/ou $\mathrm{Fe}$, elementos não detectados nas análises efetuadas. Por outro lado, o hábito prismático hexagonal observado nas imagens de MEV aponta o grupo do rabdo- fânio como o mais provável para classificação do mineral fosfático.

A gênese dos minerais do grupo do rabdofầnio tem sido relacionada a processos hidrotermais ou intempéricos, sendo esta origem comumente indicada pelas características geológicas intrínsecas dos depósitos que contêm os fosfatos. Assim, vários são os exemplos de rabdofânio intempérico, associado ou não a outros fosfatos, em perfis de solo desenvolvidos a partir de rochas graníticas (e.g. BANFIELD \& EGGLETON 1989), alcalinas (LOTTERMOSER 1990) e basaltos (COTTEN et al. 1995). Rabdofânio de origem hidrotermal foi reconhecido em rochas hidrotermalizadas em ambiente vulcânico (e.g. FODOR et al. 1987) e em porções hidrotermalizadas de plutons graníticos (e.g. RICKETTS 1994).

No Brasil, rabdofânio calcífero contendo Ce foi descrito por SOUBIÈs et al. (1991, 1992) em perfil de solo na jazida de fosfato e titânio, desenvolvida na borda norte do complexo ultramáfico-alcalino carbonatítico da região de Tapira (MG). Nesta área, várias gerações de minerais secundários (apatita, anatásio, rabdofânio) se formaram a partir da alteração de apatita e perovskita primárias contidas em piroxenitos e peridotitos. Os autores sugeriram origem hidrotermal para a solução percolante, as quais deveriam ser fortemente ácidas ou alcalinas para a liberação de grandes quantidades de fosfato. Por considerar que houve condições paleoclimáticas e geoquímicas favoráveis, FERRARI (2000) admitiu origem supérgena, a partir da alteração meteórica da apatita e perovskita primárias, para estes minerais formados em perfis lateríticos. VALARELLI (1971) e CARVALHO (1974a,b) assinalaram a ocorrência de rabdofầnio em carbonatitos silicificados no complexo ultramáfico-alcalino de Catalão I (GO), atribuindo também origem intempérica a partir da rocha carbonatítica.

O rabdofânio aqui identificado é um mineral autigênico, como indicam suas feições texturais (disposição em feixes de cristais prismáticos euedrais), sendo sua origem claramente associada à apatita detrítica. É bastante provável que parte dos componentes químicos $(\mathrm{Ca}, \mathrm{ETR}$, $\left.\left(\mathrm{PO}_{4}\right)^{3-}\right)$ do rabdofânio tenha sido provida pela apatita; no entanto, os estudos petrográficos mostraram que a dissolução dos grãos de apatita é uma feição subordinada, existindo muitos clastos inalterados. Estas evidências sugerem a contribuição de soluções capazes de dissolver a apatita, liberando os íons e complexos aniôni- 
cos, e também de fornecer uma cota dos elementos necessários para a cristalização do rabdofânio, inclusive sobre os grãos de quartzo e a matriz argilosa.

No caso da Formação Resende, a origem da solução que permitiu a precipitação do rabdofầnio ainda é uma questão em aberto. Ainda que uma origem intempérica de idade recente não seja de todo descartada, esta parece não ser o caso, tendo em vista que os processos intempéricos atuais têm promovido a completa caulinização destas rochas, que adquirem cores avermelhadas a amareladas em função da quantidade de óxidos e hidróxidos de ferro gerados por esta alteração de caráter essencialmente laterítico, desenvolvida em clima tropical. Tendo em vista que este fosfato encontra-se em lamitos não afetados pela alteração intempérica atual (preservação da cor verde original da rocha; presença de paleossolos carbonáti$\cos$ - calcretes - preenchendo rachaduras e vênulas no lamito argiloso e cimentação calcítica do lamito arenoso), o caráter restrito da ocorrência no contexto da bacia e a proximidade do depósito com zonas de falha, admite-se a origem hidrotermal como a mais provável.

Assim, considera-se a possibilidade destes fosfatos de terras raras com cálcio terem sido formados a partir da alteração da apatita detrítica por solução hidrotermal. Estes fluidos teriam dissolvido a apatita detrítica, liberando fosfato, cálcio e terras raras leves, os quais também proviriam em parte da própria solução, ocasionando a precipitação de rabdofânio sobre os grãos detríticos, incluindo a apatita, e a matriz argilosa.

Tendo em vista a constituição esmectítica da matriz argilosa dos lamitos da Formação Resende (SANT'ANNA 1999), exclui-se, a princípio, a influência de soluções hidrotermais fortemente ácidas na alteração da apatita detrítica e geração do rabdofânio, uma vez que estes fluidos também teriam provocado a alteração destes argilominerais. Ademais, a presença de três maciços alcalinos nas vizinhanças da Bacia de Resende e de derrame ankaramítico na Bacia de Volta Redonda poderia sugerir, preliminarmente, um contexto geológico favorável para o fornecimento de fluidos alcalinos, cuja percolação nos sedimentos lamíticos seria facilitada pelas várias reativações dos falhamentos que controlam o arcabouço e truncam os depósitos da bacia. Destaca-se ainda o enriquecimento em elementos terras raras apresentado pelas rochas alcalinas, quando comparadas a granitos, basal- tos, gabros e a crosta terrestre (HENDERSON 1984, TAYLOR \& McLENNAN 1985).

\section{CONCLUSÕES}

O mineral fosfático, contendo cálcio e terras raras leves ( $\mathrm{La}, \mathrm{Nd}$ ), encontrado em depósito lamítico do sistema de leque aluvial mediano da Formação Resende, é atribuído ao grupo do rabdofânio, tendo em vista suas características morfológicas e composição química. Este fosfato encontra-se intimamente associado a apatita detrítica, a qual deve ter fornecido, pelo menos em parte, os elementos químicos necessários para sua cristalização.

Em função do contexto geológico da ocorrência, a gênese deste fosfato foi relacionada à percolação de soluções hidrotermais, as quais promoveriam a dissolução dos grãos detríticos de apatita, liberando cálcio, fosfato e terras raras e ainda contribuiriam com alguns dos elementos envolvidos na precipitação do rabdofânio.

O caráter alcalino da solução que percolou os sedimentos é sugerido pela constituição esmectítica da matriz argilosa e presença de carbonatos nestes lamitos. Nesse sentido, a abundância em rochas alcalinas no embasamento da Bacia de Resende e a presença de derrame de lava ankaramítica intercalado na Formação Resende na Bacia de Volta Redonda demonstram a favorabilidade desse ambiente geológico para disponibilização de soluções alcalinas. Adicionalmente, as fraturas presentes nos depósitos sedimentares seriam um meio propício para percolação destas soluções.

\section{AGRADECIMENTOS}

Agradecimentos são devidos aos Profs. Drs. Daniel Atencio e Maria Cristina Motta de Toledo do IG-USP, pelas sugestões apresentadas, ao Dr. Victor Velázquez Fernandez pelo auxílio nas descrições petrográficas e discussões durante a confecção deste artigo e aos dois revisores anônimos pela análise crítica do trabalho. Os autores agradecem ainda o apoio financeiro da FAPESP através de projeto de auxílio à pesquisa (95/3381-5) e projetos de infra-estrutura (95/5635-4 e 97/10669-0). 


\section{REFERÊNCIAS BIBLIOGRÁFICAS}

AMADOR, E.S. 1975. Estratigrafia e sedimentação da Bacia de Resende, RJ. Rio de Janeiro: Anais da Academia Brasileira de Ciências, 47:181-225.

BANFIELD, J.F. \& EGGLETON, R. 1989. Apatite replacement and rare earth mobilization, fractionation, and fixation during weathering. Clarkson: Clays and Clay Minerals, 37(2):113-127.

CARVALHO, W.T.1974a. Aspectos geológicos e petrográficos do Complexo UltramáficoAlcalino de Catalão I, GO. In: SBG, CONGRESSO BRASILEIRO DE GEOLOGIA, 28, Porto Alegre, Anais, 5: 107-123.

1974b. Recursos minerais do Complexo Ultramáfico-Alcalino de Catalão I, GO. In: SBG, CONGRESSO BRASILEIRO DE GEOLOGIA, 28, Porto Alegre, Anais, 6: 165-184.

COIMBRA, A.M. \& RICCOMINI, C. 1985. Considerações paleoambientais sobre as ocorrências de caliche nas bacias de Curitiba (PR), Taubaté (SP) e Resende (RJ). Rio de Janeiro: Anais da Academia Brasileira de Ciências, 57(3-4):517-518.

COTTEN, J.; LE-DEZ, A.; BAU, M.; CAROFF, M.; MAURY, R.C.; DULSKI, P.; FOURCADE, S.; BOHN, M.; BROUSSE, R. 1995. Origin of anomalous rare-earth element and yttrium enrichments in subaerially exposed basalts; evidence from French Polynesia. Amsterdam: Chemical Geology, 119(1-4):115-138.

DE PUTTER, T.; CHARLET, J.M.; QUINIF, Y. 1999. REE, Y and U concentration at the fluid-iron oxide interface in late cenozoic cryptodolines from Southern Belgium. Amsterdam: Chemical Geology, 153(1-4):139-150.

DIXON, J.B. \& WEED, S.B. 1989. Minerals in soil environments. SSSA, Wisconsin, $1244 \mathrm{p}$.

FERRARI, A. \& SILVA, M.A.M. 1997. Bacia do Macacu (RJ): proposta de uma nova bacia do Rift Continental do Sudeste do Brasil. In: SBG, SIMPÓSIO DE GEOLOGIA DO SUDESTE, 5, Itatiaia, Atas, p.32-34.
FERRARI, V.C. 2000. Fosfatos primários e secundários nos perfis de intemperismo sobre os maciços alcalino-carbonatíticos de Juquiá (SP), Anitápolis (SC) e Tapira (MG). Instituto de Geociências, Universidade de São Paulo, São Paulo, Tese de Doutoramento, 241p.

FODOR, R.V.; BAUER, G.R.; JACOBS, R.S.; BORNHORST, T.J. 1987. Kahoolawe island, Hawaii: tholeiitic, alkalic, and unusual hydrothermal (?) "enrichment" characteristics. Amsterdam: Journal of Volcanology abd Geothermal Research, 31(1-2):171-176.

GAINES, R.V.; SKINNER, H.C.W.; FOORD, E.E; MASON, B.; ROSENZWEIG, A. 1997. Dana's New Mineralogy: The System of Mineralogy of James Dwight Dana and Edward Salisbury Dana. John Wiley \& Sons, New York, 1819p.

HENDERSON, P. 1984. Rare earth element geochemistry. Elsevier, Amsterdam, 510 p.

INSTITUTO DE PESQUISAS TECNOLÓGICAS DO ESTADO DE SÃO PAULO S/A. 1983. Estudos geológico-tectônicos na Bacia de Resende (RJ) e sedimentos terciários da área de Volta Redonda (RJ) e Bacia de Taubaté (área de Cruzeiro - SP). Relatório $n^{\circ} 17.737$, v.1, 132p.

KLEIN, C. \& HURLBUT JR., C. 1999. Manual of mineralogy. John Wiley \& Sons, New York, 681p.

KRAVCHENKO, S.M. \& POKROVSKY, B.G. 1995. The Tomtor alkaline ultrabasic massif related REE-Nb deposits, northern Siberia. Lancaster: Economic Geology, 90(3):676-689.

LAUAR, C.R.M. 1988. Paleomagnetismo e correlações com idades radiométricas: alguns exemplos. Instituto de Geociências, Universidade de São Paulo, São Paulo, Seminário, 29p.

LIMA, M.R. \& AMADOR, E.S. 1985. Análise palinológica de sedimentos da Formação Resende, Terciário do Estado do Rio de Janeiro, Brasil. In: Coletânea de trabalhos paleontológicos, Brasília, DNPM. Série Geologia, 27, Seção Paleontologia e Estratigrafia, 2, p.371-378. 
LIMA, M.R.; RICCOMINI, C.; SOUZA, P.A. 1994. Palinologia de folhelhos do Gráben de Casa de Pedra, Terciário do Estado do Rio de Janeiro, Brasil. São Leopoldo: Acta Geologica Leopoldensia, 27(39/2):485-504.

LOTTERMOSER, B.G. 1990. Rare-earth element mineralization within the Mt. Weld carbonatite laterite, Western Australia. Amsterdam: Lithos, 24(2):151-167.

MACHADO FILHO, L.; RIBEIRO, M.W.; GONZALEZ, S.R.; SCHENINI, C.A.; SANTOS NETO, A.; PALMEIRA, R.C.B.; PIRES, J.L.; TEIXEIRA, W.; CASTRO, H.E.F. 1983. Geologia. In: MINISTÉRIO DAS MINAS E ENERGIA. 1983. Projeto Radambrasil, Levantamento de Recursos Minerais, Folhas SF. 23/24 Rio de Janeiro/Vitória. vol.32, p.27-304.

MEINTZER, R.E. \& MITCHELL, R.H. 1988. The epigene of allanite. Ontario: Canadian Mineralogist, 26: 945-955.

MELO, M.S.; RICCOMINI, C.; HASUI, Y.; ALMEIDA, F.F.M.; COIMBRA, A.M. 1985a. Geologia e evolução do sistema de bacias tafrogênicas continentais do sudeste do Brasil. São Paulo: Revista Brasileira de Geociências, 15:193-201.

MOONEY, R.C.L. 1950. X-ray diffraction study of cerous phosphate and related crystals. 1. Hexagonal modification. Cambridge: Acta Crystallographica, 3:337-341

NRIAGU, J.O. 1984. Phosphate minerals: their properties and general modes of occurrence. In: J.O. Nriagu \& P.B. Moore (ed.) Phosphate minerals. Springer-Verlag, Berlin, p.1-136.

RICCOMINI, C. 1989. O Rift Continental do Sudeste do Brasil. Instituto de Geociências, Universidade de São Paulo, São Paulo, Tese de Doutoramento, 256p.

\& COIMBRA, A.M. 1992. Geologia da bacia sedimentar. In: A. Negro JR., A.A. Ferreira, U.R. Alonso, P.A. Luz (eds.) Solos da Cidade de São Paulo. ABMS/ABEF, São Paulo, p.37-94.

RICCOMINI, C.; COIMBRA, A.M.; SANT'ANNA, L.G.; BRANDT NETO, M.; VALARELLI, J.V. 1996. Argilominerais do paleolago Tremembé e sistemas depo- sicionais relacionados (Paleógeno, Rift Continental do Sudeste do Brasil). São Paulo: Revista Brasileira de Geociências, 26(3):167-180.

RICCOMINI, C.; MELO, M.S.; ALMEIDA, F.F.M.; MIOTO, J.A.; HASUI, Y. 1983. Sobre a ocorrência de um derrame de ankaramito na Bacia de Volta Redonda (RJ) e sua importância na datação das bacias tafrogências continentais do sudeste brasileiro. In: SBG, SIMPÓSIO REGIONAL DE GEOLOGIA, 4, São Paulo, Resumos, p.23-24.

RICKETTS, A. 1994. The alteration of allanites in the Castro granite pluton, central Idaho. Idaho, University of Idaho, Idaho, Master Dissertation, 220p.

SANT'ANNA, L.G. 1999. Geologia, mineralogia e gênese das esmectitas dos depósitos paleogênicos do Rift Continental do Sudeste do Brasil. Instituto de Geociências, Universidade de São Paulo, São Paulo, Tese de Doutoramento, 293p.

SLUKIN, A.D. 1994. Bauxite deposits with unusually high concentrations of REE, $\mathrm{Nb}$, Ti and Th, Chadobets Uplift, Siberian Platform. Lancaster: International Geology Review, 36(2):179-193.

SONOKI, I.K. \& GARDA, G.M. 1988. Idades $\mathrm{K}$-Ar de rochas alcalinas do Brasil meridional e Paraguai oriental: compilação e adaptação às novas constantes de decaimento. São Paulo, Bol. IG-USP, Série Cientifica, 19:63-85.

SOUBIÈS, F.; MELFI, A. J.; DELVIGNE, J.; SARDELA, I. A. 1991. Comportamento geoquímico dos elementos terras raras nos alteritos da jazida de fosfato e titânio de Tapira (Minas Gerais, Brasil): a importância dos fosfatos. São Paulo: Revista Brasileira de Geociências, 21(1):3-16.

SOUBIÈS, F.; MELFI, A. J.; AUTEFAGE, F.; FONTAN, F. 1992. Deux phosphates secundaires des alterations du Complexe ultramafique-alcalin de Tapira, Minas Gerais, Bresil: calcio-rhabdophane et kolbeckite. In: REUNION SOCIETÉ FRANÇAISE DE MINERALOGIE ET CRISTALLOGRAPHIE, Orléans, s/p.

TAYLOR, S.R. \& McLENNAN, S.M. 1985. The continental crust: its composition and evolution. Blackwell, London, 312p. 
VALARELLI, J.V. 1971. O minério de nióbio, titânio e terras raras de Catalão, GO. Instituto de Geociências, Universidade de São Paulo, São Paulo, Tese de Livre Docência 104p.

YAMAMOTO, I.T. 1995. Palinologia das bacias tafrogênicas do sudeste (bacias de
Taubaté, São Paulo e Resende): análise bioestratigráfica integrada e interpretação paleoambiental. Instituto de Geociências e Ciências Exatas, Universidade Estadual Paulista, Rio Claro, Dissertação de mestrado, 217p.

\section{Endereço dos autores:}

Lucy Gomes Sant'Anna e Claudio Riccomini- Instituto de Geociências, Universidade de São Paulo, Caixa Postal 11.348, São Paulo, SP, Brasil. E-mails: 1santann@hotmail.com, comin@usp.br 